\title{
Erratum to: A social-ecological approach to landscape epidemiology: geographic variation and avian influenza
}

\author{
Graeme S. Cumming • Celia Abolnik - Alexandre Caron • Nicolas Gaidet • \\ John Grewar • Eléonore Hellard • Dominic A. W. Henry • \\ Chevonne Reynolds
}

Published online: 7 May 2015

(C) Springer Science+Business Media Dordrecht 2015

\section{Erratum to: Landscape Ecol \\ DOI 10.1007/s10980-015-0182-8}

Unfortunately, in the original publication the coauthor's (J. Grewar) affiliation has been published incorrectly. It is corrected in this erratum.

The online version of the original article can be found under doi:10.1007/s10980-015-0182-8.

G. S. Cumming $(\bowtie) \cdot$ E. Hellard .

D. A. W. Henry · C. Reynolds

DST/NRF Centre of Excellence, Percy FitzPatrick

Institute, University of Cape Town, Rondebosch,

Cape Town 7701, South Africa

e-mail: graeme.cumming@uct.ac.za

Present Address:

G. S. Cumming

ARC Centre of Excellence for Coral Reef Studies, James

Cook University, Townsville, QLD 4811, Australia

C. Abolnik

Department of Production Animal Studies, Faculty of

Veterinary Science, University of Pretoria, Onderstepoort,

Pretoria 0110, South Africa
A. Caron - N. Gaidet

UPR AGIRs, CIRAD, Montpellier, France

A. Caron

UPR AGIRs, CIRAD-RP-PCP, Harare, Zimbabwe

A. Caron

Mammal Research Institute, University of Pretoria, Pretoria 0110, South Africa

J. Grewar

Department of Agriculture, Government of the Western

Cape, Cape Town, South Africa 